\title{
FAKTOR-FAKTOR YANG MEMPENGARUHI IBU TERHADAP PEMAKAIAN ALAT KONTRASEPSI IMPLAN DI WILAYAH KERJA PUSKESMAS MEDAN JOHOR PANGKALAN MASYUR TAHUN 2017
}

\author{
Sartini Bangun \\ Jurusan Kebidanan Poltekkes Kemenkes Medan
}

\begin{abstract}
Abstrak
Salah satu cara menurunkan angka kematian ibu (AKI) adalah dengan cara membatasi jumlah kelahiran dengan cara keikutsertaan akseptor atau keluarga berencana. Pelayanan keluarga berencana (KB) yang berkualitas belum sepenuhnya menjangkau seluruh wilayah nusantara. Paradigma program KB telah mempunyai visi dari mewujudkan NKKBS mewujudkan keluarga yang berkualitas tahun 2015. yaitu keluarga yang sejahtera, sehat, maju, mandiri, memilih jumlah anak yang ideal. berwawasan ke depan, bertanggung jawab dan harmonis, sehingga diperlukan KB .Capaian pelayanan KB lebih banyak menggunakan pil dan suntik, sehingga penulis ingin meneliti Faktor-faktor yang mempengaruhi ibu terhadap pemakaian alat kontrasepsi implant di wilayah kerja Puskesmas Medan Johor Kelurahan Pangkalan Masyhur Tahun 2017'. Penelitian deskriptif analitikpopulasi 68 akseptor implant (total popolasi sampling) dengan kuisioner, analisis univariat dan bivariat. Dari 69 responden yang berpengetahuan cukup 49,3\%, yang berpendidikan menengah 56,5\%, usia 20 - 35 tahun 46,4\%, yang multiparitas 53,7\% dan yang memperoleh informasi dari madia massa 55,1\%. Analisis Chi-square: pengetahuan (22,601 > 5,991),pendidikan (16,924 $>5.991)$,usia $(10,826>5,991)$,paritas $(6,111>5,991)$,sumber informasi $(9,421>5,991)$ dengan kata lain semua varibel menunujukkan nilai $\mathrm{X}^{2}$ hitung. $\mathrm{X}^{2}$ tabel artinya semua varibel berhubungan dengan pemakaian implant (Ha diterima). Simpulan: sebagian besar responden berpengetahuan cukup dan tingkat pendidikan menengah, disarankan agar masa usia transisi menggunakan KB implant.
\end{abstract}

Kata kunci : Keluarga Berencana, Kontrasepsi Implant

\section{PENDAHULUAN}

Angka Kematian Ibu (AKI) di Indonesia relatif tinggi hingga mencapai 307 per 100.000 kelahiran hidup. Penurunan AKI serta peningkatan derajat kesehatan ibu menjadi prioritas utama dalam pembangunan bidang kesehatan di Indonesia. Salah satu upaya yang dapat dilakukan dapat mewujudkan dalam bentuk safe motherhoodaplikasinya dengan mencegah melahirkan usia terlalu muda dan jumlah anak yang terlalu banyak (Prawirohardjo, 2007).

Paradigma program KB telah mempunyai visi dari mewujudkan NKKBS menjadi visi untuk mewujudkan keluarga berencana yang berkualitas tahun 2015. Keluarga yang berkualitas adalah keluarga yang sejahtera, sehat, maju, mandiri, memilih jumlah anak yang ideal. berwawasan ke depan, bertanggung jawab dan harmonis. Visi tersebut dijabarkan dalam 6 visi yaitu memberdayakan masyarakat, menggalang kemitraan, dalam peningkatan kesejahteraan, kemandirian dan ketahanan keluarga. Meningkatkan kegiatan khusus kualitas KB dan kesehatan reproduksi, meningkatkan promosi, perlindungan dan upaya mewujudkan hak-hak reproduksi dan meningkatkan upaya pemberdayaan perempuan untuk mewujudkan kesetaraan dan keadilan gender melalui program $\mathrm{KB}$ serta mempersiapkan sumber daya manusia yang berkualitas sejak pembuahan dan kandungan sampai pada usia lanjut (Hartanto, 2012).

Angka kematian ibu dan perinatal merupakan ukuran penting dalam menilai keberhasilan pelayanan kesehatan dan keluarga berencana Penggunaan kontrasepsi jangka panjang seperti implant yang lebih unggul karena mempunyai daya perlindungan yang lebih besar. Dalam pemakaian implant hanya perlu 1 kali pemasangan sehingga tidak ada faktor lupa seperti penggunaan pil, Namun demikian masyarakat masih lebih banyak menggunakan kontrasepsi jangka pendek (BKKBN, 2015).

Dari profil sumut pada tahun 2016, berdasarkan data kabupaten / kota jumlah peserta KB baru adalah $12,10 \%$ hanya sedikit peningkatan yang terjadi dari tahun 2015 dengan jumlah $11,84 \%$ sebesar $0,26 \%$. Berdasarkan Jenis alat kontrasepsi yang digunakan peserta KB selama tahun 2016 tidak jauh berbeda bila dibandingkan dengan tahun 2015 alat kontrasepsi yang paling banyak dipilih adalah pil dan suntik (Dinkes Sumut, 2016).

Berdasarkan data yang diambil dari Puskesmas Medan Johor Tahun 2016 untuk wilayah Pangkalan Masyhur bahwa yang menggunakan kontrasepsi pil 880 orang, suntik 380 orang, implant 69 orang, IUD 57 orang dan kondom 55 orang. 
Berdasarkan latar belakang tersebut maka penulis tertarik untuk melakukan penelitian tentang "Faktor-faktor yang mempengaruhi ibu terhadap pemakaian kontrasepsi implant di Wilayah Kerja Puskesmas Medan Johor Kelurahan Pangkalan Masyuhur Tahun 2017.'

Kontrasepsi Implant adalah metode kontrasepsi yang diinsersikan pada subdermal, yang mengandung progestin dengan masa kerja panjang, dosis rendah, dan reversibel untuk wanita (Speroff, 2015).

Ciri-ciri kontrasepsi yang diperlukan:

1. Efektivitas sangat tinggi. akseptor memang tidak mengharapkan punya anak lagi.

2. Dapat dipakai untuk jangka panjang.

3. Tidak menambah kelainan yang sudah ada.

\section{Jenis-jenis Implant}

Menurut Saifuddin mengemukakan kontrasepsi implant terdiri dari beberapa jenis yaitu:

1. Norplant

Norplant merupakan suatu system "lepas-lambat" yang menggunakan pipa silastic yang permeablel terhadap molekul steroid, untuk memberikan kadar progestin sintetik yang stabil di dalam sirkulasi selama penggunaan bertahun-tahun. Pada tahun 1975, uji coba pertama jangka panjang dimulai dengan 6 batang silastik berongga dengan panjang $3,4 \mathrm{~cm}$ dengan diameter $2,4 \mathrm{~mm}$ yang diberi nama Norplant. Tiap kapsul berisi $38 \mathrm{mg}$ progesterone levonorgestrel berfungsi selama 5 tahun.

2. Implanon

Implanon adalah batang tunggal berisi $68 \mathrm{mg}$ etonogestrel yang dipasang secara subdermal dan mendapat lisensi selama 3 tahun. Panjang batang tersebut $4 \mathrm{~cm}$ dan berdiameter $2 \mathrm{~mm}$ dan dilengkapi aplikator steril yang sudah diisi. Implanon

3. Jadena dan indoplant

Terdiri dari 2 batang yang diisi dengan $75 \mathrm{mg}$ levonorgestrel dengan lama kerja 3 tahun.

\section{Waktu Penggunaan}

Waktu yang paling baik untuk penggunaan implant adalah :

1. Setiap saat selama siklus haid hari ke-2 sampai hari ke-7. .

2. Insersi dapat dilakukan setiap saat, asal saja diyakini tidak terjadi kehamilan. Bila diinsersi setelah hari ke-7 siklus haid, klien jangan melakukan hubungan seksual, atau menggunakan metode kontrasepsi lain untuk 7 hari saja.

3. Bila menyusui antara 6 minggu sampai 6 bulan pascapersalinan, insersi dapat dilakukan setiap saat. Bila menyusui penuh, klien tidak perlu memakai metode kontrasepsi lain.

4. Bila setelah 6 minggu melahirkan dan telah terjadi haid kembali, insersi dapat dilakukan setiap saat, tetapi jangan melakukan hubungan seksual selama 7 hari atau menggunakan metode kontrasepsi lain untuk 7 hari saja.
5. Bila klien menggunakan kontrasepsi hormonal dan ingin menggantinya dengan implant, insersi dapat dilakukan setiap saat, asal saja diyakini klien tersebut tidak hamil.

6. Bila kontrasepsi sebelumnya adalah kontrasepsi suntikan, implant dapat diberikan pada saat jadwal kontrsepsi suntikan tersebut.

7. Bila kontrasepsi sebelumnnya adalah kontrasepsi nonhormonal (kecuali AKDR) dan klien ingin menggantinya dengan implant, insersi dapat dilakukan setiap saat, asal saja diyakini klien tidak hamil.

8. Bila kontrasepsi sebelumnya adalah AKDR dan klien ingin menggantinya dengan implant, implant dapat diinsersikan pada saat haid hari ke-7 dan klien jangan melakukan hubungan seksual selama 7 hari atau gunakan metode kontrasepsi lain untuk 7 hari saja. AKDR segera dicabut.

9. Pascakeguguran, implant dapat segera diinsersikan.

\section{Mekanisme Kerja Implant}

1. Mengentalkan lendir serviks

2. Mengganggu proses pembentukan endometrium sehingga sulit terjadi implantasi.

3. Mengurangi transportasi sperma.

4. Menekan ovulasi.(Saifuddin, 2006)

\section{Keuntungan}

Efektifitas tinggi, Perlindungan dalam jangka panjang, Pengembalian tingkat kesuburan yang cepat setelah pencabutan, Bebas dari pengaruh estrogen, Tidak mengganggu kegiatan senggama, Tidak mengganggu produksi ASI, Klien hanya perlu kembali ke klinik apabila ada keluhan, dan dapat dicabut sesuai dengan waktu yang diinginkan

\section{Kerugian}

Membutuhkan seorang professional terlatih untuk memasang dan melepas implant, Perdarahan menstruasi tidak teratur, seperti emenorea, perdarahan bercak, Efek samping minor, seperti sakit kepala, jerawat, dan kemungkinan rasa tidak nyaman atau infeksi pada tempat pemasangan.

\section{KERANGKA BERFIKIR}

\begin{tabular}{|l|l|}
\hline 1.Pengetahuan \\
2.Pendidikan \\
3.Umur \\
4.Paritas \\
5.Sumber informasi
\end{tabular}$\rightarrow \begin{aligned} & \text { Kontrasepsi } \\
& \text { Implan } \\
& \end{aligned}$

\section{METODE}

\section{Jenis Penelitian dan Desain Penelitian}

Penelitian ini merupakan penelitian deskriptif analitik bertujuan untuk mengetahui faktor-faktor yang mempengaruhi ibu terhadap pemakaian kontrasepsi implant 


\section{Lokasi dan waktu Penelitian}

Penelitian dilakukan di Wilayah Kerja Puskesmas

Medan Johor kelurahan Pangkalan Masyhur Tahun 2017, mulai juli s/d agustus 2017.

\section{Populasi dan Sampel}

Populasi sebanyak 69 orang (Total Populasi Sampel).Data menggunakan kuesionerdan wwancara singkat.

\section{Jenis dan Cara Pengumpulan Data}

Data dikumpulkan menggunakan kuisioner dan wawancara singkat dan Pengolahan Datamelalui langkah :Editing, Coding, Entry Data,

Tabulating

Analisis data

Analisis data univariat disajikan secara deskriptif dan factor yang berpengaruh uji Chi-Square dengan rumus :

$\mathrm{X}^{2}=\sum \frac{(0-E)^{2}}{E}$

\section{HASIL DAN PEMBAHASAN}

Berdasarkan hasil penelitian yang berjudul "Faktor-faktor yang mempengaruhi ibu terhadap pemakaian alat kontrasepsi implant di wilayah kerja Puskesmas Medan Johor Kelurahan Pangkalan Masyhur Tahun 2017" kepada 69 responden dan didapat hasil distribusi responden berdasarkan pengetahuan, pendidikan, umur ibu, paritas, dan sumber informasi yang diuraikan sebagai berikut :

Tabel 4.1 Pengaruh Pengetahuan Terhadap Pemakaian Alat Kontrasepsi Implant Di Wilayah Kerja Puskesmas Medan Johor Kelurahan Pangkalan Masyhur Tahun 2017

\begin{tabular}{|c|c|c|c|c|c|c|c|c|}
\hline \multirow{3}{*}{ Pengetahuan } & \multicolumn{4}{|c|}{ Pemakaian Implan } & \multirow{2}{*}{\multicolumn{2}{|c|}{ Jumlah }} & \multirow{3}{*}{$\begin{array}{c}\mathbf{X}^{2} \\
\text { Hitung }\end{array}$} & \multirow{3}{*}{$\begin{array}{c}\mathbf{X}^{2} \\
\text { Tabel }\end{array}$} \\
\hline & \multicolumn{2}{|c|}{ Tidak memakai } & \multicolumn{2}{|c|}{ Memakai } & & & & \\
\hline & $\mathbf{n}$ & $\%$ & $\mathbf{n}$ & $\%$ & $\mathbf{n}$ & $\%$ & & \\
\hline Baik & 3 & 4,3 & 15 & 21,7 & 18 & 26,1 & \multirow{4}{*}{22,601} & \multirow{4}{*}{5,991} \\
\hline Cukup & 5 & 7,2 & 29 & 42,0 & 34 & 49,3 & & \\
\hline Kurang & 13 & 18,8 & 4 & 5,8 & 17 & 24,6 & & \\
\hline Jumlah & 21 & 30,4 & 48 & 69,6 & 69 & 100,0 & & \\
\hline
\end{tabular}

Tabel 4.2. Distribusi Pengaruh Pendidikan Terhadap Pemakaian Alat Kontrasepsi Implant Di Wilayah Kerja Puskesmas Medan Johor Kelurahan Pangkalan Masyhur Tahun 2017

\begin{tabular}{|c|c|c|c|c|c|c|c|c|}
\hline \multirow{3}{*}{ Pendidikan } & \multicolumn{4}{|c|}{ Pemakaian Implant } & \multirow{2}{*}{\multicolumn{2}{|c|}{ Jumlah }} & \multirow{3}{*}{$\begin{array}{c}\mathbf{X}^{2} \\
\text { Hitung }\end{array}$} & \multirow{3}{*}{$\begin{array}{c}\mathbf{X}^{2} \\
\text { Tabel }\end{array}$} \\
\hline & \multicolumn{2}{|c|}{ Tidak memakai } & \multicolumn{2}{|c|}{ Memakai } & & & & \\
\hline & $\mathbf{n}$ & $\%$ & $\mathbf{n}$ & $\%$ & $\mathbf{n}$ & $\%$ & & \\
\hline Dasar & 11 & 15,9 & 4 & 5,8 & 15 & 21,7 & \multirow{4}{*}{16,924} & \multirow{4}{*}{5,991} \\
\hline Menengah & 8 & 11,6 & 31 & 44,9 & 39 & 56,5 & & \\
\hline Tinggi & 2 & 2,9 & 13 & 18,8 & 15 & 21,7 & & \\
\hline Jumlah & 21 & 30,4 & 48 & 69,6 & 69 & 100,0 & & \\
\hline
\end{tabular}

Tabel 4.3. Distribusi Pengaruh Umur Ibu Terhadap Pemakaian Alat Kontrasepsi Implant Di Wilayah Kerja Puskesmas Medan Johor Kelurahan Pangkalan Mansyur Tahun 2010

\begin{tabular}{|c|c|c|c|c|c|c|c|c|}
\hline \multirow{3}{*}{ Umur } & \multicolumn{4}{|c|}{ Pemakaian Implant } & \multirow{2}{*}{\multicolumn{2}{|c|}{ Jumlah }} & \multirow{3}{*}{$\begin{array}{c}\mathbf{X}^{2} \\
\text { Hitung }\end{array}$} & \multirow{3}{*}{$\begin{array}{c}\mathbf{X}^{2} \\
\text { Tabel }\end{array}$} \\
\hline & \multicolumn{2}{|c|}{ Tidak memakai } & \multicolumn{2}{|c|}{ Memakai } & & & & \\
\hline & $\mathrm{n}$ & $\%$ & $\mathbf{n}$ & $\%$ & n & $\%$ & & \\
\hline$<20$ tahun & 2 & 2,9 & 9 & 13,0 & 11 & 15,9 & \multirow{4}{*}{10,826} & \multirow{4}{*}{5,991} \\
\hline $20-35$ tahun & 5 & 7,2 & 14 & 20,3 & 32 & 46,4 & & \\
\hline$>35$ tahun & 14 & 20,3 & 12 & 17,4 & 26 & 37,7 & & \\
\hline Jumlah & 21 & 30,4 & 48 & 69,6 & 69 & 100,0 & & \\
\hline
\end{tabular}

Tabel 4.4. Distribusi Pengaruh Paritas Ibu Terhadap Pemakaian Alat Kontrasepsi Implant Di Wilayah Kerja Puskesmas Medan Johor Kelurahan Pangkalan Masyhur Tahun 2017

\begin{tabular}{|c|c|c|c|c|c|c|c|c|}
\hline \multirow{3}{*}{ Paritas } & \multicolumn{4}{|c|}{ Pemakaian Implant } & \multirow{2}{*}{\multicolumn{2}{|c|}{ Jumlah }} & \multirow{3}{*}{$\begin{array}{c}\mathrm{X}^{2} \\
\text { Hitung }\end{array}$} & \multirow{3}{*}{$\begin{array}{c}\mathbf{X}^{2} \\
\text { Tabel }\end{array}$} \\
\hline & \multicolumn{2}{|c|}{ Tidak memakai } & \multicolumn{2}{|c|}{ Memakai } & & & & \\
\hline & $\mathbf{n}$ & $\%$ & $\mathbf{n}$ & $\%$ & $\mathbf{n}$ & $\%$ & & \\
\hline Primipara & 10 & 14,5 & 9 & 13,0 & 19 & 27,5 & \multirow{4}{*}{6,111} & \multirow{4}{*}{5,991} \\
\hline Multipara & 8 & 11,6 & 29 & 42,0 & 37 & 53,6 & & \\
\hline Grandemultipara & 3 & 23,1 & 10 & 14,5 & 13 & 18,9 & & \\
\hline Jumlah & 21 & 30,4 & 48 & 69,6 & 69 & 100,0 & & \\
\hline
\end{tabular}


Tabel 4.5. Distribusi Pengaruh Sumber Informasi Terhadap Pemakaian Alat Kontrasepsi Implant Di Wilayah Kerja Puskesmas Medan Johor Kelurahan Pangkalan Masyhur Tahun 2017

\begin{tabular}{|c|c|c|c|c|c|c|c|c|}
\hline \multirow{3}{*}{ Sumber Informasi } & \multicolumn{4}{|c|}{ Pemakaian Implant } & \multirow{2}{*}{\multicolumn{2}{|c|}{ Jumlah }} & \multirow{3}{*}{$\begin{array}{c}\mathbf{X}^{2} \\
\text { Hitung }\end{array}$} & \multirow{3}{*}{$\begin{array}{c}\mathbf{X}^{2} \\
\text { Tabel }\end{array}$} \\
\hline & \multicolumn{2}{|c|}{ Tidak memakai } & \multicolumn{2}{|c|}{ Memakai } & & & & \\
\hline & $\mathbf{n}$ & $\%$ & n & $\%$ & $\mathbf{n}$ & $\%$ & & \\
\hline Tenaga kesehatan & 2 & 2,9 & 10 & 14,5 & 12 & 17,4 & \multirow{4}{*}{9,421} & \multirow{4}{*}{5,991} \\
\hline Lingkungan & 11 & 15,9 & 8 & 11,6 & 19 & 27,5 & & \\
\hline Media massa & 8 & 11,6 & 30 & 43,5 & 38 & 55,1 & & \\
\hline Jumlah & 21 & 30,4 & 48 & 69,6 & 69 & 100,0 & & \\
\hline
\end{tabular}

\section{PEMBAHASAN}

Menurut Notoadmodjo Tahun 2005, pengetahuan merupakan hasil dari tahu dan terjadi setelah orang melakukan pengindraan terhadap suatu objek tertentu. Pengetahuan merupakan komponen yang sangat pentingdiperlukan sebagai dorongan psikis dalam menemukan rasa percaya diri, sehingga dikatakan bahwa pengetahuan merupakan stimulus terhadap tindakan seseorang.

Pengetahuan responden rendah menyebabkan kurang mengetahui pentingnya menggunakan kontrasepsi khususnya kontrasepsi implant (Schrahman, 2009).

Dalam peneliti ini pengetahuan cukup 56,5\%, berpengetahuan rendah $24,6 \%$ yang tidak menggunakan kontrasepsi implant $18,8 \%$ sedangkan yang berpengetahuan baik 24,6\% dan tidak menggunakan kontrasepsi implan 18,8\%.

Artinya lebih banyak ibu-ibu berpengetahuan kurang tidak menggunakan kontrasepsi implan sama halnya ibu berpengetahuan baik lebih banyak tidak menggunakan kontrasepsi implan. Hal ini disebabkan kemungkinan karena belum dipahami secara jelas keuntungan kontrasepsi implan, dan kemungkinan ada rasa takut karena pemasangannya ditanam dibah kulit.

Tingkat pendidikan dalam penelitian ini diperoleh tingkat pendidikan menengah 56,5\% dan yang tidak menggunakan kontrasepsi implan 11,6 \% sedangkan yang berpendidikan tinggi $21, \& \%$, yang menggunakan kontraspsi implan $18,8 \%$, artinya responden yang berpendidikan tinggi lebih banyak menggunakan kontrasepsi implan karena responden memahami betul keuntungan yang baik dari penggunakan kontrasepsi implan.

Menurut Hurlock (2002), menyatakan bahwa semakin tinggi pendidikan seseorang maka pengetahuan dan tindakannya semakin baik.

Karena tingkat pendidikan semakin tinggi, semakin mudah menerima dan menyerap informasi, sehingga dapat mempertimbangkan keuntungan dan kerugian juga efek samping serta efesiensi penggunaan yang ada dalam kontrasepsi implant.

Hasil penelitian usia reproduksi sehat $46,4 \%$, yang tidak menggunakan kontrasepsi implant 7,2\%, sedangkan pada usia > 35 tahun $37,7 \%$ yang tidak menggunakan implant 20,3\%, pada hal sesungguhnya pada usia lebih 35 tahun sebaiknya memnggunakan kontrasepsi implant karena risiko yang lebih sedikit.

Sesuai dengan pendapat dari BKKBN (2007) bahwa jumlah anak yang dilahirkan merupakan faktor yang cukup tinggi di dalam menentukan keikutsertaan dalam program KB. Dalam ponelitian ini multiparitas 53,6\% dan tidak menggunakan kontrasepsi implan 11,6\% sedangkanpada grandemultipara $18,9 \%$ yang tidakmenggunakan kontrasepsi implan $23,1 \%$, hal ini tampak berbanding terbalik karena pada usia grandemultiparitas sebaik tidak melahirkan, mengingat jumlah anak tidak diharapkan bahkan jauh lebih baik lagi kalau melakukan kontarasepsi mantap.

Informasi tentang kontrasepsi implan diperoleh melalui media massa $55,1 \%$, yang tidak menggunakan kontrasepsiimplan 11,6 \% sedangkan yang memperoleh informasi dari lingkungan 27,5\% dan tidak menggunkan kontrasepsi implan 15,(\%. Disini dapat kita katakan bahwa informasi tentang implan jauh lebih baik diperolek dari tenaga kesehatan dan midia massa, yamng informasi dari lingkungan kurang bisa dipertanggung jawabkan dan penuh keraguan sehingga hasil informasi dari lingkungan tinggi yang tidak menggunakan kontrasepsi implan.

Informasi penting sebagai konsekuensi logis perkebangan dibidang ilmu pengetahuan dan teknologi yang sangat cepat. Informasipun menjadi berkembang sangat cepat sehingga orang sering mengatakan bahwa adanya ledakan pengetahuan menimbulkan ledakan informasi.

\section{KESIMPULAN}

Hasil penelitian dapat disimpulkan:

1. Paling banyakresponden berpengetahuan cukup. Hasil analisis menunjukkan nilai $\mathrm{X}^{2}$ hitung $>\mathrm{X}^{2}$ tabel artinya Ho ditolak artinya ada pengaruh pengetahuan responden terhadap pemakaian kontrasepsi implant.

2. Responden paling banyak dengan pendidikan menengah. Hasil analisa uji statistik Chi-square diperoleh nilai $\mathrm{X}^{2}$ hitung $>\mathrm{X}^{2}$ tabel dimana Ho ditolak artinya ada pengaruh antara pendidikan responden terhadap pemakaian implant.

3. Responden paling banyak berumur 20-35 tahun. Hasil analisa Chi-square diperoleh nilai $\mathrm{X}^{2}$ hitung > $\mathrm{X}^{2}$ tabel dimana Ho ditolak artinya ada pengaruh umur responden terhadap pemakaian implant.

4. Responden paling banyak multipara. Hasil analisa uji statistik Chi-squarediperoleh nilai $\mathrm{X}^{2}$ hitung $>\mathrm{X}^{2}$ tabel dimana Ho ditolak artinya ada pengaruh paritas responden terhadap pemakaian kontrasepsi implant.

5. Responden paling banyak menerima informasi dari media massa. Hasil analisa diperoleh nilai $\mathrm{X}^{2}$ hitung $>\mathrm{X}^{2}$ tabel dimana Ho ditolak artinya ada pengaruh 
sumber informasi terhadap pemakaian kontrasepsi implant.

\section{SARAN}

1. Diharapkan agar masa transisi petugas kesehatan sebaiknya lebih mempromosikan KB implant.

2. Dianjurkan untuk semua pasangan usia reproduksi sehat agar memakai akseptor yang efektif terpilih.

\section{DAFTAR PUSTAKA}

Arum,Dyah Noviawati Setya. 2008. Panduan lengkap pelayanan $K B$ terkini. Mitra cendikia:Jogjakarta.

BKKBN. 20015. Kebijakan dan Strategi Nasional Kesehatan Reproduksi Indonesia. Jakarta.http://www.BKKBN.go.id.mei 2005. 2017. Keluarga Berencana dan Kesehatan Reproduksi. http://www.BKKBN.go.id

Burns. 2000. Pemberdayaan Wanita Dalam Bidang Kesehatan. Andi : Yogyakarta

Depkes RI. 2015. Kebijakan dan strategi Nasional Kesehatan Reproduksi Indonesia. Jakarta.http://www.depkes RI.go.id.mei 2015.

Everett, Suzanne. 2015. Kontrasepsi \& kesehatan seksual reproduktif. EGC: Jakarta.

Hartanto, hanafi. 2012. Keluarga berencana dan kontrasepsi. Pustaka sinar harapan: Jakarta

Hidayat, A.Aziz Alimul. 2017. Metode penelitian kebidanan \& teknik analisis data. Salemba medika: Jakarta
Hurlock. 2002. Psikologi Perkembangan. Erlangga : Jakarta

Keraf, S. 2014. Ilmu Pengetahuan. Kanisius: Yogyakarta

Manuaba, Ida Bagus Gde. 1998. Ilmu Kebidanan, Penyakit Kandungan \& Keluarga Berencana untuk Pendidikan Bidan. EGC: Jakarta

Notoatmodjo, Soekidjo. 2007. Pendidikan dan Prilaku Kesehatan, cetakan 1. Rineka Cipta : Jakarta . 2012. Metodologi penelitian kesehatan. PT Rineka Cipta: Jakarta

Rahaju, Firrar Artmi. 2009. Kehamilan yang tidak di inginkan. Http://www.forum pembaca kompas.com

Saifuddin, Abdul Bari. 2006. Buku panduan praktis pelayanan kontrasepsi. Yayasan Bina pustaka sarwono : Jakarta Yayasan Bina Pustaka Sarwono: Jakarta

Schrachman, Wilbur. 2009. Kehamilan Yang Tidak Diinginkn.www.gizi net.com

Siswono. 2015. Kematian ibu. http://www.suara pembaharuan.com/ News/09/02/index.htm

Speroff, Leon. 1996. Pedoman klinis kontrasepsi. EGC: Jakarta.

Syafei, Chandra. 2008. Dinas kesehatan provinsi sumatera utara.http://www.prov

sumut.com./oktober 2009

WHO.1994. Ragam metode kontrasepsi. EGC:Jakarta. 